\title{
REPENSANDO A AGRICULTURA: O ENFOQUE DA SUSTENTABILIDADE COMO PADRÃO ALTERNATIVO À AGRICULTURA MODERNA
}

\author{
Francisco das Chagas Silva Souza
}

Mestre em Desenvolvimento e Meio Ambiente (UERN); Professor de História no CEFETRN/UNED; chagasouza@uol.com.br

Recebido em agosto/2004 e Aceito em outubro/2004

\begin{abstract}
RESUMO
A modernização da agricultura ocorrida nos países em desenvolvimento, na segunda metade do século XX, trouxe como efeito o aumento da produção agrícola, porém agravou os danos ambientais e os problemas sociais. Este artigo tem como objetivo analisar a agricultura sustentável, apresentando-a como uma alternativa viável para a redução dos problemas advindos com a Revolução Verde. A coleta de informações foi realizada através de revisão bibliográfica. Concluímos que a agricultura sustentável supera a concepção de desenvolvimento agrícola associado principalmente ao aumento da produtividade. Seu principal objetivo é a manutenção da produtividade agrícola com o mínimo possível de impactos ambientais e com retornos econômico-financeiros adequados à meta de redução da pobreza atendendo, dessa maneira, às necessidades sociais e econômicas das populações rurais.
\end{abstract}

Palavras-chaves: agricultura, sustentabilidade, impactos, desenvolvimento, agroecologia.

\section{REPENSANDO LA AGRICULTURA: EL ENFOQUE DE LA SOSTENTABILIDAD COMO PATRÓN ALTERNATIVO A LA AGRICULTURA MODERNA}

\section{RESUMEN}

La modernización de la agricultura ocurrida en los países en desarrollo, en la segunda mitad del siglo XX, trajo como efecto el aumento de la producción agrícola, pero agravó los daños ambientales y los problemas sociales. Este artículo tiene como objetivo analizar la agricultura sostenible, presentándola como una alternativa viable para la reducción de los problemas advenidos con la Revolución Verde. La coleta de informaciones fue realizada a través de revisión bibliográfica. Concluimos que la agricultura sostenible supera la concepción de desarrollo agrícola asociado principalmente al aumento de la productividad. Suyo principal objetivo es la manutención de la productividad agrícola con el mínimo posible de impactos ambientales y con retornos económico-financieros adecuados a la meta de reducción de la pobreza atendiendo, de esa manera, a las necesidades sociales y económicas de las poblaciones rurales.

Palabras llaves: agricultura, sostentabilidad, impactos, desarrollo, agroecología. 


\section{INTRODUÇÃO}

Tornou-se comum vermos os veículos de imprensa divulgar matérias sobre o êxito da agricultura brasileira nos últimos anos. Tais reportagens exibem grandes máquinas agrícolas semeando ou colhendo grãos, trabalhadores pulverizando as plantações, empresários satisfeitos com os resultados das safras, quebras recordes de produtividade.

Esse quadro caracteriza a agricultura moderna cuja introdução no Brasil se dá a partir da década de 50 do século passado, num processo conhecido como Revolução Verde. Assim, a agricultura tradicional, baseada na utilização intensiva de recursos naturais, foi progressivamente substituída por um sistema agrícola cujas bases estão assentadas no forte uso de máquinas, implementos, equipamentos e insumos, além de técnicas mais sofisticadas para obter maior racionalização das atividades. Logo se comemorou o aumento da produtividade e crescia cada vez mais a esperança em resolver o problema da fome. Entretanto, não tardou a aparecer os efeitos danosos do modelo produtivo que fora adotado: poluição química, erosão dos solos, contaminação dos alimentos, destruição da fauna e flora, dentre outros. As críticas que foram feitas à agricultura moderna possibilitaram o surgimento de um outro paradigma que se contrapõe ao anterior: a agricultura sustentável.

Este trabalho tem por objetivo apresentar a origem da agricultura sustentável e identificá-la como alternativa viável para a mitigação dos impactos ambientais no campo e para alcançar um desenvolvimento rural, melhorando a qualidade de vida das populações envolvidas.

\section{A AGRICULTURA MODERNA: IMPACTOS SÓCIO-AMBIENTAIS}

O "pacote tecnológico” da Revolução Verde trouxe, para o Brasil e para os outros países em desenvolvimento, um processo de transformação radical na agricultura, com vistas a integrar-se à indústria. Era a penetração do capitalismo no campo, o qual, para elevar a produtividade do trabalho agrícola, lançou mão dos recursos da sua indústria: adubos, máquinas, defensivos etc. Desta forma, o desenvolvimento das relações de produção capitalistas no setor rural se fez "industrializando” a própria agricultura.

Assim, se antes disso, o processo produtivo da agricultura era extremamente dependente dos fatores naturais (clima, relevo, solo, temperatura, topografia etc), agora, com a mecanização intensa, fertilizantes, pesticidas e manipulação genética, a possibilidade de aproveitamento dos solos menos férteis e de ocupação intensiva de territórios, antes desprezados para tal atividade, deixa de ser um sonho e torna-se realidade. Pode-se dizer que a tecnologia e o capital passam a subordinar, em parte, a própria natureza, reproduzindo artificialmente algumas das condições necessárias à produção agrícola, a qual, desde então, torna-se cada vez mais dependente dos insumos gerados pela indústria, cuja produção passa a transformar todo o conjunto de instrumentos de trabalho agrícola. (Elias:1996).

É como se o sistema capitalista passasse a "fabricar" uma Natureza que fosse adequada à produção de maiores lucros. Assim, se uma determinada região é seca, tome lá uma irrigação para resolver a falta de água; se é um brejo, lá vai uma draga 
resolver o problema do excesso de água; se a terra não é fértil, aduba-se; e assim por diante. (Graziano da Silva, 1982: 45)

Os resultados quantitativos desse modelo, no que diz respeito à produtividade e à lucratividade, foram brilhantes. Nas últimas cinco décadas, a produção de gêneros importantes mais do que dobrou; a de cereais triplicou. Conforme Hawken et al (2000:177), nos últimos trinta anos, o número de calorias alimentares disponíveis por pessoa na Terra aumentou $13 \%$ apesar do rápido crescimento demográfico, valendo salientar que o aumento da produção mundial de víveres resultou de plantações mais produtivas e de amadurecimento mais rápido e não do aumento da área cultivada, pois esta terra custaria mais para irrigar, drenar e vincular ao mercado do que o justificariam os preços das safras. "Só a irrigação respondeu por mais da metade do crescimento da produção mundial de alimentos de meados da década de 1960 e da de 1980. No período 1961-96, o emprego dos fertilizantes à base de nitrogênio aumentou 645 por cento." (ibid: 178)

Todavia, os problemas sociais e ambientais advindos com a nova tecnologia são também imensos e traduziu-se em brutais índices de erosão dos solos, no comprometimento da qualidade e da quantidade de recursos hídricos para a agricultura, na devastação sistemática de florestas e campos nativos, no empobrecimento da diversidade genética de plantas e animais, na contaminação dos alimentos consumidos pela população, no desprezo ao conhecimento tradicional dos lavradores e aos tipos de culturas desenvolvidas pelos mesmos.

Hawken et al (op. cit:179) afirma que o setor alimentício consume entre 10 a $15 \%$ da energia em todos os países industrializados, sendo que os EUA superam estes números. Neste país a atividade agrícola continua usando muitas - talvez dez - vezes mais energia de combustível fóssil na produção de víveres do que o retorno que obtém em energia alimentar.

Assistimos, hoje, o comprometimento dos solos férteis em todo o mundo. Um terço do extrato superior do solo dos EUA desapareceu e uma parte considerável está degradada. O solo das Grandes Planícies semi-áridas perdeu 71\% da produtividade 28 anos depois de ter sido desrelvado. Para se ter uma idéia da dimensão do problema, vejamos as informações dadas por Hawken et al (idem)

Na década de 1980, o equivalente a um caminhão basculante carregado de solo passava, por segundo, diante de Nova Orleans no rio Mississipi.Uma década depois, 90\% das áreas cultiváveis continuavam perdendo solo ainda mais depressa - em média dezessete vezes mais depressa - do que se formava solo novo, incorrendo em custos projetados de 44 bilhões de dólares nos próximos vinte anos.

A cada ano, bilhões de toneladas de terra fértil são erodidas e transportadas para os rios, trazendo o assoreamento das suas margens. Bley Jr (1999:24), com base em dados da Embrapa, afirma que, no Brasil, as perdas já atingem 840 milhões de toneladas anuais (t/ano) e estão aumentando, com a abertura de novas frentes agropecuárias no CentroOeste e na Amazônia. No Rio Grande do Sul, essas perdas já alcançam 20,1 toneladas por hectares (t/ha) nas culturas da soja. O total estadual é de 250 milhões de t/ano. No estado 
de São Paulo perde-se $10 \mathrm{~kg}$ de solo fértil por quilograma de grão produzido - ou 200milhões de t/ano. Na tentativa de recuperar a fertilidade dos solos são usados em todo o país até $1,27 \mathrm{~kg}$ de fertilizantes químicos por hectare, a um custo de mais de US\$ 2 bilhões por ano. Estudos revelam que no Paraná, entre 1970 e 1986, o consumo de NPK - adubos industriais à base de nitrogênio $(\mathrm{N})$, fósforo $(\mathrm{P})$ e potássio $(\mathrm{K})$ - passou de 100 mil para $600 \mathrm{mil} \mathrm{t} / \mathrm{ano}$. De acordo com a Embrapa, cerca de metade do fertilizante utilizado no conjunto de todas as culturas não atingem o alvo, ou seja, não é assimilada pelas plantas. (ibid:25)

Segundo ainda Blay Jr, na Índia a erosão já afeta 57\% das terras, comprometendo 11 das principais culturas do país. Ali, a área erodida dobrou em 18 anos. A cada ano, aquele país perde mais de $1 \%$ do solo fértil e, junto, mais de 20 milhões de toneladas de NPK. No total, a perda causada pela erosão representa cerca de $1 \%$ a $2 \%$ do PIB anual indiano. No Haiti, a situação é ainda mais grave: metade das terras agricultáveis já se perdeu. No mundo, estima-se a perda de $1 \%$ das terras férteis a cada ano. Além disso, cerca de $25 \%$ das terras do planeta estão em processo de desertificação ou definitivamente perdidas. No caso brasileiro, a desertificação é um fato evidente no Nordeste. Em $181 \mathrm{mil} \mathrm{km}^{2}$ da área nordestina, ações humanas, aliadas a fatores naturais, geram impactos difusos e perdas econômicas de US\$ 800 milhões por ano. As regiões mais comprometidas estão em Gibués (PI), Irauçuba (CE), Seridó (RN) e Cabrobó (PE). (Idem)

A irrigação é um dos elementos mais importantes dentro do padrão de agricultura moderna e um dos responsáveis pelo aumento da produtividade. Em conformidade com Hawken et al (op. cit.:180), apesar de ser aguado apenas 16\% da terra arável, três quartos da qual nos países em desenvolvimento, por outro lado produz $40 \%$ do alimento do mundo. "Em muitas áreas importantes os lençóis subterrâneos foram bombardeados até o esgotamento - extraídos do solo feito petróleo." A salinização, juntamente com outros problemas advindos de projetos de irrigação e drenagem mal implementados já prejudicam mais de um décimo da terra arável irrigada do planeta. "De um nono da terra do mundo que era considerada arável em 1990, pouco se conserva realmente sadio, a maior parte está estressada e é generalizada a aceleração das perdas.” (ibid.:181)

A Revolução Verde trouxe também a especialização de culturas. A destruição dos habitats nativos trouxe como efeito a redução da diversidade genética. Num sistema agrícola industrializado, incentiva-se a produção em larga escala das variedades mais produtivas e especializadas. Desta forma, as monoculturas comerciais destroem as tradições locais de subsistência, geralmente diversificadas. "Só na África subsaariana contém mais de cem desses cereais esquecidos e mais de 2 mil plantas comestíveis abandonadas: não mais que um punhado é objeto de pesquisa significativa.” (Hawken et al, op. cit.: 182)

Na medida em que reduz a diversidade de culturas, as monoculturas são também responsáveis por outro dano ao meio ambiente: a proliferação de doenças e pragas. As doenças das plantas prejudicam ou destroem 13\% das plantações mundiais; os insetos, $15 \%$; as ervas daninhas, $12 \%$; sendo que ao todo, dois quintos das safras do planeta se perdem nas plantações. O uso de biocidas não parece ser a solução mais viável.

Por volta de 1948, no início da era dos pesticidas sintéticos, os Estados Unidos gastavam 19 milhões de quilos de inseticidas por ano e perdiam para os insetos $7 \%$ da safra antes da colheita. Atualmente, com o emprego cerca de vinte vezes maior de 
inseticidas - quase 400 milhões de quilos por ano (...), os insetos ficam com 13\%, sendo que as perdas totais, nas safras norteamericanas, são $20 \%$ mais elevadas do que eram quando se iniciou a roda-viva dos pesticidas. (idem)

Tal fato ocorre porque os insetos adaptam-se e tornam-se resistentes a poderosíssimos venenos mais depressa do que se consegue inventar novos. Ao se perturbar a concorrência entre as espécies e ao eliminar os predadores naturais, os pesticidas geralmente transformam os insetos antes inofensivos em pragas deletérias.

Hawken at al (op. cit.: 190) faz ainda outra observação importante: a monocultura contribui também para alterar o clima da Terra. Isso se explica porque a redução da diversidade de culturas e a substituição dos ciclos nutrientes naturais por sintéticos, faz com que a biomassa existente de bactérias, fungos e a biota restante do solo interrompa o seu funcionamento e, ao morrer, eles se oxidam ou apodrecem, liberando carbono no ar. Com o objetivo de repor a fertilidade do solo, aplicam-se quantidades cada vez maiores de agroquímicos, sendo que estes ao serem fabricados consumem cerca de $2 \%$ da energia industrial total.

Apesar da Revolução Verde ter se apresentado na segunda metade do século XX como a solução para os problemas de abastecimento e da fome, logo vão surgir as primeiras críticas a esse padrão produtivo como, por exemplo, a publicação, em 1962, da obra Silent Spring (Primavera Silenciosa), de Rachel Carson, a qual alertava para o perigo que se supunha o uso indiscriminado de pesticidas. As críticas vão se tornar mais organizadas nas décadas de 1980 e 1990, como veremos a seguir.

\section{AGRICULTURA E SUSTENTABILIDADE}

\section{Desenvolvimento sustentável}

A preocupação com problemas ambientais agravados pelos modelos de desenvolvimento com crescimento ilimitado geraram uma série de encontros internacionais nas últimas décadas do século passado. Em 1972, a Conferência de Estocolmo foi um marco fundamental nesses debates. As décadas seguintes à de 1970 foram muito frutíferas quanto ao debate sobre o ecodesenvolvimento, termo criado em 1973, pelo canadense Maurice Strong. Esta expressão foi aos poucos sendo substituída pela noção de desenvolvimento sustentável ${ }^{1}$. É merecedor de destaque o Relatório Brundtland (1987)², também conhecido como Nosso Futuro Comum, o qual é o resultado do trabalho da Comissão Mundial (da ONU) sobre o Meio Ambiente e o Desenvolvimento (UNCED). O relatório parte de uma visão complexa das causas dos problemas sócio-econômicos e ecológicos da sociedade

${ }^{1}$ Barbieri (op. cit. 23) indica que o termo desenvolvimento sustentável foi usado pela primeira vez em 1980 no documento denominado World Conservation StrategyI, produzido pela IUCN e World Wildlife Found (hoje, World Wide Found for Nature - WWF) por solicitação do Programa das Nações Unidas para o Meio Ambiente - PNUMA.

2 É importante evidenciar também a Declaração de Cocoyok, em 1974; o Relatório DagHammarskjöld, em 1975; a Conferência Intergovernamental sobre Educação Ambiental, em Tibilisi, URSS, em 1977; e a Rio 92, considerado o mais importante de todos os eventos internacionais a enfocar o desenvolvimento sustentável. 
global. Ele vê a economia, a tecnologia, a sociedade e a política como aspectos interrelacionados, e ressalta a necessidade de uma nova postura ética, caracterizada pela responsabilidade tanto entre as gerações quanto entre os membros contemporâneos da sociedade atual. (Brüseke, 1998: 33) Dessa forma, o desenvolvimento sustentável, segundo tal documento "é aquele que atende às necessidades do presente sem comprometer a possibilidade de as gerações futuras atenderem a suas próprias necessidades." (Nosso Futuro Comum, 1991: 46) Este tem dois conceitos-chave: 1- o conceito de "necessidades"3, sobretudo aquelas essenciais aos países do mundo, devendo estas receberem a máxima prioridade; 2- a noção das limitações que o estágio da tecnologia e da organização social impõe ao meio ambiente, impedindo-o de suprir às carências do presente e do futuro.

Na sua essência, "o desenvolvimento sustentável é um processo de transformação no qual a exploração dos recursos, a direção dos investimentos, a orientação do desenvolvimento tecnológico e a mudança institucional se harmonizam e reforçam o potencial presente $e$ futuro, a fim de atender às necessidades e aspirações humanas." (ibid. 49) Urge, portanto, que o mundo crie estratégias que permitam às nações substituir seus atuais processos de crescimento, geralmente destrutivos, pelo desenvolvimento sustentável, os quais devem ser pautados nos seguintes objetivos: retomar o crescimento e alterar a qualidade deste, atender às necessidades essenciais de emprego, alimentação, energia, água e saneamento; manter um nível populacional sustentável, conservar e melhorar a base de recursos, reorientar a tecnologia e administrar o risco, incluir o meio ambiente e a economia no processo de tomada de decisões. (ibid. 53)

\section{Agricultura sustentável: origens, conceitos e objetivos}

O conceito de sustentabilidade, a partir do Relatório Brundtland, logo se expandiu para os diversos países, principalmente os do chamado Primeiro Mundo, tornando-se um novo paradigma da sociedade moderna. A expressão também foi incorporada ao setor agropecuário por um número crescente de profissionais, pesquisadores e produtores, face a necessidade de um novo padrão produtivo que respeite o ambiente, como sucedâneo ao modelo de agricultura "moderna" ou "convencional” até então vigente. Entretanto, apontar as características básicas desse "novo padrão" não foi tarefa fácil. O que se percebeu foi que a discussão em torno da noção que ficou internacionalmente conhecida como “agricultura sustentável” permanecia cercada de dúvidas e de contradições, tanto no campo conceitual como operacional. (Ehlers, 1998: 84)

Contribuiu para a rápida disseminação, a criação, nos Estados Unidos, de dois importantes programas. Em 1988, o United States Departament of Agriculture (USDA), criou um programa de pesquisa e treinamento intitulado LISA ou Low-Imput/Sustainable Agriculture; um ano depois, o National Research Council (NRC) publicou o Alternative Agriculture, divulgando os resultados otimistas de uma ampla pesquisa sobre quatorze propriedades alternativas nos EUA. Por influência do Programa LISA e da publicação de Agriculture Alternative, foi aprovada, em 1990, a lei agrícola norte-americana Food, Agriculture, Conservation and Trade Act (FACTA-90). Essa lei determina que o USDA

\footnotetext{
${ }^{3}$ A discussão que hoje se coloca é a dificuldade em definir essas necessidades, diferenciando as “reais” das consideradas "supérfluas”. Nas sociedades modernas, as pessoas já não definem livremente suas necessidades, havendo interferências ou pressões de várias ordens, como a propaganda, a vigência de certos padrões de consumo e comportamento etc. Estamos muito longe de nos preocuparmos apenas com o comer, o vestir e o ter onde morar, embora milhões de indivíduos nem isso tenham assegurado.
} 
deve promover programas de pesquisa, educação e extensão voltados para a agricultura sustentável. Para esse fim, o programa LISA, foi expandido, passando a ser conhecido como Sustainable Agriculture Research and Education - SARE. A mudança de atitude no meio da pesquisa agropecuária desse país deve-se, dentre outras, às seguintes razões: os problemas energéticos e ambientais do padrão moderno, a crescente pressão da opinião pública, particularmente das ONGs, sobre as questões ambientais e a salubridade dos alimentos. (Ehlers, 1995: 14-15)

É dentro desse contexto que se desenhou uma grande quantidade de definições para explicar o que se entende por agricultura sustentável, quase todas expressando uma insatisfação com o status quo da agricultura. Paralelamente a isso, defendia-se a necessidade de um novo modelo de agricultura que, que garantisse a segurança alimentar e que não agredisse o meio ambiente, mantendo as características dos agroecossistemas por tempo indeterminado.

Dentre as várias tentativas, as definições de agricultura sustentável propostas pela FAO e pela NRC são as mais aceitas internacionalmente e servem para um balizamento para essa discussão. (Veiga, citado por Ehlers, 1998) Assim, para o NRC:

Agricultura sustentável não constitui algum conjunto de práticas especiais, mais sim um objetivo: alcançar um sistema produtivo de alimento e fibras que: (a) aumente a produtividade dos recursos naturais e dos sistemas agrícolas, permitindo que os produtores respondam aos níveis de demanda engendrados pelo crescimento populacional e pelo desenvolvimento econômico; (b) produza alimentos sadios, integrais e nutritivos que permitam o bem-estar humano; (c) garanta uma renda líquida suficiente para que os agricultores tenham um nível de vida aceitável e possam investir no aumento da produtividade do solo, da água e de outros recursos e (d) corresponda às normas e expectativas da comunidade. (NRC, citado por Ehlers, 1998: 91-92)

No mesmo ano, 1991, a principal organização mundial da área, a FAO, reuniu-se na Europa e lançou a Declaração de Den Bosh que define a agricultura sustentável como:

O manejo e a conservação da base de recursos naturais, e a orientação da mudança tecnológica e institucional, de maneira a assegurar a obtenção e a satisfação contínua das necessidades humanas para as gerações presentes $e$ futuras. Tal desenvolvimento sustentável (na agricultura, na exploração florestal, na pesca) resulta na conservação do solo, da água e dos recursos genéticos animais e vegetais, além de não degradar o ambiente, ser tecnicamente apropriado, economicamente viável e socialmente aceitável. (FAO, citado por Ehlers, 1998: 92)

Contudo, dada a amplitude de conceitos de "agricultura sustentável” não foi ainda selado algum tipo de consenso. Por sua abrangência, tais conceitos têm abrigado tanto os setores mais “conservadores", quanto os mais "radicais". A variedade de grupos envolve também uma diversidade de tendências religiosas, ideológicas e visões de mundo que muitas vezes chegam a ser antagônicas. 
Para os mais "conservadores”, como as empresas produtoras de insumos, por exemplo, a noção de agricultura sustentável é uma sinonímia do modelo convencional, porém dotado de maior eficiência e "racionalidade". Seria mais um conjunto de práticas bem-definidas, que podem ser julgadas como mais ou menos sustentáveis conforme as previsões sobre a durabilidade dos recursos naturais de que fazem uso.

A redução do uso de insumos industriais (low imput agriculture), a aplicação mais eficiente ou mesmo a substituição dos agroquímicos por insumos biológicos ou biotecnológicos seriam suficientes para a consolidação do novo paradigma. Nesse caso, a agricultura sustentável é algo bem mais palpável, um objetivo de curto prazo. (Ehlers, 1998: 93)

Diametralmente oposto é o entendimento de "agricultura sustentável” para os mais "radicais”, agrupando, principalmente organizações não-governamentais. Para estes, essa agricultura é vista como uma possibilidade de se promover transformações sociais, econômicas e ambientais em todo o sistema agroalimentar, através das quais se eliminarão a fome e a miséria, melhorar-se-á a qualidade de vida para milhões de pessoas, democratizar-se-á o uso da terra, ao passo que se consolidará uma nova ética social mais igualitária. Estes são alguns dos desafios contidos na noção de desenvolvimento e agricultura sustentável.

Trata-se, portanto, de uma noção bem mais ambiciosa que pressupõe, inclusive, a superação do próprio industrialismo. Nesse caso, a noção de sustentabilidade entra para o conjunto das grandes utopias modernas, como a justiça social, a liberdade ou a democracia e só pode ser entendida como um objetivo, certamente, a logo prazo." (Ehlers, 1998: 93. Grifos do autor)

Vê-se, a partir do exposto, que agricultura sustentável não pode ser claramente definida, por ser um conceito complexo e em disputa. Hoje todos os organismos multilaterais (ONU, Banco do Brasil, FAO etc) e mesmo o governo brasileiro adotaram "desenvolvimento sustentável” e "agricultura sustentável” como jargão. Termos como "novos paradigmas” e "holismo", tornaram-se comuns serem alardeados, mas há uma enorme diferença entre o discurso e a prática.

Dado ao caráter polêmico em torno do termo, Almeida (1998:47) informa, com base no Departamento de Agricultura dos EUA, o que não é agricultura sustentável.

[ela não é] uma ruptura com a agricultura moderna, ...[não é] outro nome para agricultura orgânica; ...[não é] somente para pequenos produtores; ...[não é] somente para propriedades de criação animal; ...[não é] um passo atrás; ...[não é] uma panacéia para todos os problemas ambientais; ...[não é] uma solução completa para todos os problemas de lucratividade agrícola; ...[não é] uma solução para problemas orçamentários do Departamento de Agricultura. 
É digno ressaltar que a contestação à agricultura convencional não é um fato novo. O que se verifica, hoje, é que ele tem conseguido terreno fértil para se expandir: a participação dos órgãos internacionais supracitados, o apoio de empresas estatais e privadas, a participação de grande número de ONGs, no Brasil e no mundo, entre outros fatores. Contudo, isso nem sempre foi assim. Na década de 1920, surgiam, quase simultaneamente, alguns movimentos contrários à adubação química e que valorizavam o uso da matéria orgânica e de outras práticas culturais favoráveis aos processos biológicos. Esses movimentos rebeldes podem ser agrupados em quatro grandes vertentes. Na Europa, temse a agricultura biodinâmica, a agricultura orgânica e a agricultura biológica. No Japão, surgiu outra vertente, a agricultura natural.

Durante décadas esses movimentos foram hostilizados tanto pela comunidade científica como pelo setor produtivo e se mantiveram à margem do cenário agrícola mundial, em verdadeiros "guetos". Nos anos 1970, muitos dos efeitos adversos da agricultura moderna foram denunciados. Tal fato, associado ao movimento de contracultura - no qual os valores da sociedade moderna eram duramente contestados - contribuíram para o fortalecimento das vertentes dissidentes, cujo conjunto passou a ser chamado de “agricultura alternativa”. (Ehlers, 1998: 89)

Com a publicação do documento Nosso futuro comum (Relatório Brundtland) e com a Rio-92, a noção de sustentabilidade, apesar das imprecisões do termo, tornou-se mais usual, passando os movimentos que compunham a agricultura alternativa, pela sua semelhança, a serem denominados de "agricultura sustentável”.

Na década de 1980, através de estudos publicados no México e na Espanha, vai se configurando um referencial teórico cujo sintetizador é Miguel Altieri, o qual denominamos de "agroecologia”. Altieri (1995: 6), assim a define:

A agroecologia é uma ciência que apresenta uma série de princípios e metodologias para estudar, analisar, dirigir, desenhar e avaliar agroecossistemas. Portanto, utiliza-se de um enfoque científico, que tem suas próprias ferramentas, teorias $e$ hipóteses, o que lhe permite trabalhar no âmbito dos agroecossistemas e no desenvolvimento de sistemas agrícolas complexos e diversificados. A agroecologia é, pois, uma ciência, com uma série de princípios; não uma prática ou um sistema de produção. A agricultura orgânica, a agricultura alternativa, a agricultura biodinâmica ou a agricultura natural e outros termos existentes são um conjunto de práticas e tecnologias que permitem a utilização de certos insumos, e não a de outros. No contexto da agricultura orgânica, os produtos já estão regulamentados. Existe uma listagem de produtos sintéticos absolutamente proibidos $e$ outra, de produtos permitidos.

Portanto, a nova abordagem procura integrar os princípios agronômicos, ecológicos e socioeconômicos à compreensão e avaliação do efeito das tecnologias sobre os sistemas agrícolas e a sociedade como um todo. Ao serem tomados como estudo os agroecossistemas, supera-se a visão unidimensional - genética, agronomia, edafologia - e se inclui dimensões ecológicas, sociais e culturais. Os pesquisadores devem penetrar nos conhecimentos e nas técnicas dos agricultores e desenvolver agroecossistemas com uma 
dependência mínima de insumos agroquímicos e energéticos externos. "O objetivo é trabalhar com e alimentar sistemas agrícolas complexos onde as interações ecológicas $e$ sinergismos entre os componentes biológicos criem, eles próprios, a fertilidade do solo, a produtividade e a proteção das culturas.” (Altieri, 2000: 18)

Jesus (op. cit. 23) considera a agroecologia o paradigma emergente, substituto da agricultura industrial ou convencional. Pode ser entendida como uma justaposição de duas palavras, uma latina agro (relativa a agricultura), e outra grega ecologia, que por sua vez é formada por duas outras palavras gregas, eco (oikos, que significa casa) e logia (logos, que significa razão, estudo). Agroecologia, nesse sentido, seria "uma abordagem ecológica em relação à agricultura, buscando entender as biointerações que ocorrem nos sistemas agrícolas e os impactos da agricultura nos ecossistemas". ${ }^{4}$

Altieri propõe o desenvolvimento de técnicas que conciliem a atividade agrícola e a manutenção das características naturais e ecológicas do ambiente, sem desprezar os componentes sociais e econômicos. Propunha-se, portanto, uma adaptação da atividade agrícola ao meio, e não ao contrário como apregoava a "Revolução Verde”. Eis o princípio básico da agroecologia. Assim, para Ehlers (2001: 29) a principal meta da agroecologia é a resolução dos problemas da sustentabilidade, a qual só será possível se forem consideradas as questões econômicas e sociais.

Altieri (1995:6) enfatiza a sua preocupação com propósito de valorizar os aspectos sócioculturais da produção agrícola.

(...) se definirmos a agricultura sustentável como a agricultura socialmente justa, economicamente viável, culturalmente aceitável $e$ ambientalmente sã, teremos também de definir todos esses termos, porque, em muitos casos, promove-se um padrão de agricultura que tem sentido pelo aspecto ambiental, mas pelo lado social, não tem. Por exemplo, a agricultura orgânica na Califórnia tem muitos elementos de sanidade ambiental positivos, porque não contaminam, etc. Entretanto, ela se baseia na exploração da mão-de-obra mexicana. O mesmo acontece, atualmente, com a agricultura de larga escala nos Estados Unidos. Existe um mercado de produtos orgânicos e grandes agricultores que produzem de forma orgânica, saturando os mercados, deslocando, assim, os pequenos produtores e criando um problema tanto econômico quanto social.

Assim, a produção agrícola deixou de ser uma questão puramente técnica, englobando agora dimensões sociais, culturais, políticas e econômicas, mas apesar do interesse geral em integrar uma racionalidade econômica à produção agrícola, ainda tem se dado muito destaque para os aspectos tecnológicos. Tal aspecto é preocupante, pois numa pesquisa cuja meta seja a sustentabilidade, não se pode prescindir de uma discussão de caráter

${ }^{4}$ Segundo o autor, deve-se ter cautela para não se confundir agroecologia com ecologia agrícola, pois, se a primeira tem uma abordagem holística, buscando não se fixar apenas nas relações biofísicas ambiente-agricultura; a segunda contenta-se em especializar-se numa pequena área, limite entre a ciência agronômica e a ciência da ecologia. 
interdisciplinar. Áreas do conhecimento como biologia, ecologia, agronomia, sociologia, economia, entre outras, devem ser integradas para uma maior e melhor compreensão dos sistemas agrícolas. "o que se vê, quando se fala em desenvolvimento sustentável, são preocupações e discussões mais voltadas para o 'natural' e menos para o 'social'. A 'questão' da erosão dos solos, da contaminação dos recursos hídricos e a destruição das florestas têm predominado no debate.” (Almeida, op.cit. : 51)

Face ao exposto:

Novos agroecossitemas sustentáveis não poderão ser implementados sem uma mudança nos determinantes socioeconômicos que governam o que é produzido, como é produzido e para quem é produzido. Para serem eficazes, as estratégias de desenvolvimento devem incorporar não somente dimensões tecnológicas, mas também questões sociais $e$ econômicas. Somente políticas e ações baseadas em tal estratégia podem fazer frente aos fatores estruturais e socioeconômicos que determinam a crise agrícola-ambiental e a miséria rural que ainda existem no mundo em desenvolvimento. (Altieri, 2000:1617)

Dentro da amplitude de aspectos que a agroecologia procura dar conta, inclui-se o estudo da etnociência (o sistema de conhecimento de um grupo étnico local e naturalmente organizado). Isso se deve ao fato de que o conhecimento das pessoas do local sobre o ambiente, a vegetação, os animais e os solos pode ser bastante detalhado. "O conhecimento camponês sobre os ecossistemas geralmente resulta em estratégias produtivas multidimensionais de uso da terra, que criam, dentro de certos limites ecológicos $e$ técnicos, a auto-suficiência alimentar das comunidades em determinadas regiões." (Toledo et al, citado por Altieri, 2000: 21). Desta forma, a agricultura, antes de ser um processo ecológico, é um processo social. Os agricultores têm de estar envolvidos, desde o começo, tanto na evolução como na aplicação das tecnologias.

No fundo, o que queremos é que os camponeses se transformem em atores de seu próprio desenvolvimento. Primeiramente, devese valorizar os conhecimentos da sua capacidade inovadora e possibilitar a mobilização por meio de associações, de cooperativas ou outras formas sociais. Por outro lado, deve-se procurar capacitá-los com tecnologias, que permitam minimizar os custos de produção, visando otimizar a utilização dos recursos locais. (Altieri,1995: 09)

Tal preocupação é bastante válida, pois, como vimos, o “modelo" de desenvolvimento preconizado pela modernização agrícola despreza o conhecimento camponês, pois estes são considerados como na contramão do progresso. Eles são os "retardatários da modernização" e, portanto, devem se adequar ao padrão moderno, desenvolvimentista, visto como a única via possível e desejável.

As distinções entre as tecnologias da Revolução Verde e as da Agroecologia são assim sintetizadas por Altieri (2000:34-35). 


\begin{tabular}{|c|c|c|}
\hline CARACTERÍSTICAS & REVOLUÇÃO VERDE & AGROECOLOGIA \\
\hline \multicolumn{3}{|l|}{ TÉCNICAS } \\
\hline Cultivos afetados & Trigo, milho, arroz etc. & Todos os cultivos \\
\hline Áreas afetadas & $\begin{array}{l}\text { Na maioria, áreas planas e } \\
\text { irrigáveis }\end{array}$ & $\begin{array}{l}\text { Todas as áreas, especialmente } \\
\text { as marginais (dependentes da } \\
\text { chuva, encostas declivadas. }\end{array}$ \\
\hline Sistema de cultivo dominante & $\begin{array}{l}\text { Monocultivos geneticamente } \\
\text { uniformes }\end{array}$ & $\begin{array}{l}\text { Policultivos geneticamente } \\
\text { heterogêneos. }\end{array}$ \\
\hline Insumos predominantes & $\begin{array}{l}\text { Agroquímicos, maquinário; } \\
\text { alta dependência de insumos } \\
\text { externos e conbustível fóssil. }\end{array}$ & $\begin{array}{l}\text { Fixação de nitrogênio, controle } \\
\text { biológico de pragas, corretivos } \\
\text { orgânicos, grande dependência } \\
\text { nos recursos locais renováveis. }\end{array}$ \\
\hline \multicolumn{3}{|l|}{ AMBIENTAIS } \\
\hline Impactos e riscos à saúde & $\begin{array}{l}\text { Médios e altos (poluição } \\
\text { química, erosão, salinização, } \\
\text { resistência a agrotóxicos etc.) } \\
\text { Riscos à saúde na aplicação } \\
\text { dos agrotóxicos e nos seus } \\
\text { resíduos no alimento. }\end{array}$ & Nenhum. \\
\hline Cultivos deslocados & $\begin{array}{l}\text { Na maioria, variedades } \\
\text { tradicionais e raças locais. }\end{array}$ & Nenhum. \\
\hline \multicolumn{3}{|l|}{ ECONÔMICAS } \\
\hline Custos das pesquisas & Relativamente altos. & Relativamente baixos. \\
\hline Necessidades financeiras & $\begin{array}{l}\text { Altas. Todos os insumos } \\
\text { devem ser adquiridos no } \\
\text { mercado. }\end{array}$ & $\begin{array}{l}\text { Baixas. A maioria dos insumos } \\
\text { está disponível no local. }\end{array}$ \\
\hline Retorno financeiro & $\begin{array}{l}\text { Alto. Resultados rápidos. Alta } \\
\text { produtividade da mão-de-obra. }\end{array}$ & $\begin{array}{l}\text { Médio. Precisa de determinado } \\
\text { período para obter resultados } \\
\text { mais significativos. Baixa a } \\
\text { média produtividade da mão- } \\
\text { de-obra. }\end{array}$ \\
\hline \multicolumn{3}{|l|}{ INSTITUCIONAIS } \\
\hline Desenvolvimento tecnológico & $\begin{array}{l}\text { Setor semipúblico, empresas } \\
\text { privadas. }\end{array}$ & $\begin{array}{l}\text { Na maioria, públicas; grande } \\
\text { envolvimento de ONGs. }\end{array}$ \\
\hline \multicolumn{3}{|l|}{ SÓCIO-CULTURAIS } \\
\hline $\begin{array}{l}\text { Capacitações necessárias à } \\
\text { pesquisa }\end{array}$ & $\begin{array}{l}\text { Cultivo convencional e outras } \\
\text { disciplinas de ciências } \\
\text { agrícolas. }\end{array}$ & $\begin{array}{l}\text { Ecologia e especializações } \\
\text { multidisciplinares. }\end{array}$ \\
\hline Participação & $\begin{array}{l}\text { Baixa (na maioria, métodos de } \\
\text { cima para baixo). Utilizados } \\
\text { para determinar os obstáculos } \\
\text { à adoção das tecnologias. }\end{array}$ & $\begin{array}{l}\text { Alta. Socialmente ativadora, } \\
\text { induz ao envolvimento da } \\
\text { comunidade. }\end{array}$ \\
\hline Integração cultural & Muito baixa. & $\begin{array}{l}\text { Alta. Uso extensivo de } \\
\text { conhecimento tradicional e } \\
\text { formas locais de organização. }\end{array}$ \\
\hline
\end{tabular}

\section{CONSIDERAÇÕES FINAIS}


A agricultura sustentável rompe com a noção de desenvolvimento agrícola associado principalmente ao aumento da produtividade. Seu objetivo maior é a manutenção da produtividade agrícola com o mínimo possível de impactos ambientais e com retornos econômico-financeiros adequados à meta de redução da pobreza, assim atendendo às necessidades sociais das populações rurais.

Para a concretização de suas metas, o novo padrão de agricultura deverá superar alguns desafios, tais como: por fim à imprecisão conceitual, o que tem agregado em torno de si estudiosos de posições muitas vezes antagônicas; fortalecer a sua viabilidade técnicaprodutiva e social, justificando os seus propósitos de equidade social e de preservação ambiental; fortalecer o seu caráter indisciplinar; e influenciar na criação de políticas públicas que tenham como meta o fortalecimento da agricultura familiar, forma social de uso da terra mais adequada à noção de sustentabilidade.

\section{REFERÊNCIAS BIBLIOGRAFICAS}

ALMEIDA, Jalcione. Da ideologia do progresso à idéia de desenvolvimento (rural) sustentável. In: ALMEIDA, Jalcione e NAVARRO, Zander (org.) Reconstruindo a agricultura: idéias e ideais na perspectiva do desenvolvimento rural sustentável. 2. ed. Porto Alegre: Ed. Universidade/UFRGS, 1998. p. 33-55.

ALTIERI, Miguel A. Agricultura sustentável. (Entrevista) Jaguariúna/SP, v. 2, n.2: 05-11 , jul./dez. 1995.

Agroecologia: a dinâmica produtiva da agricultura sustentável. 2. ed. Porto Alegre:Ed. Universidade/UFRGS, 2000.

BARBIERI, José C. Desenvolvimento e meio ambiente: as estratégias de mudanças da Agenda 21. 2. ed. Petrópolis: Vozes, 1998.

BLEY JR, Cícero. Erosão solar: riscos para a agricultura nos trópicos. Ciência Hoje. Rio de Janeiro, v. 25, n. 148, p. 24-29, abr.1999.

BONILLA, José A. Fundamentos da agricultura ecológica: sobrevivência e qualidade de vida. São Paulo: Nobel, 1992.

BRÜSEKE, Franz J. O problema do desenvolvimento sustentável. In: CAVALCANTI, Clóvis (org.) Desenvolvimento e natureza: estudos para uma sociedade sustentável. 2. ed. São Paulo: Cortez; Recife-PE: Fundação Joaquim Nabuco, 1998.

COMISSÃO MUNDIAL SOBRE MEIO AMBIENTE E DESENVOLVIMENTO. Nosso futuro comum. 2. ed. São Paulo: Fundação Getúlio Vargas, 1991.

ELIAS, Denise. Globalização e modernização agrícola. Revista Paranaense de Geografia, Curitiba, n. 1, 1996. Disponível em: www.cce.ufpr.br/ agbctba/Rpg1/elias1. htm>. Acesso em: 05. março/ 2001.

EHLERS, Eduardo M. Possíveis veredas da transição à agricultura sustentável. Agricultura sustentável. Jaguariúna/SP, v. 2, n.2: 12-21, jul./dez. 1995.

O que se entende por agricultura sustentável. In: VEIGA, José E. Ciência ambiental: primeiros mestrados. São Paulo: Annablume: Fapesp, 1998.

GRAZIANO DA SILVA, José. A modernização dolorosa. Rio de Janeiro: Zahar, 1982.

HAWKEN, Paul et al. Capitalismo natural: criando a próxima Revolução Industrial. São Paulo: Cultrix, 2000.

JESUS, Eli Lino de. Da agricultura alternativa à agroecologia: para além das disputas conceituais. Agricultura sustentável. Jaguariúna/SP, v. 3, n.1/2, 13-27, jan./dez. 1996. 
SOUZA, F. C. S. 